\title{
Efficacy of nano-formulated certain essential oils on the red flour beetle Tribolium castaneum and confused flour beetle, Tribolium confusum (Coleoptera: Tenebrionidae) under laboratory and storage conditions
}

Magda Mahmoud Amin Sabbour(D)

\begin{abstract}
Abtract
Background: The confused flour beetles Tribolium confusum (Jacquelin) and red flour beetle Tribolium castaneum (Herbst) are widespread insects found in the stores and homes that attack many stored foods in several commodities. They are controlled by synthetic chemical insecticides. The natural oils give good results in controlling these pests and decreasing its infestations. The natural essential oils have a low effect on the human, non-target insects, and do not pollute the environments. This research is an alternative approach to naturally control these two stored product pests.

Methods: Nano-formulations of four essential oils, namely, coriander, black seed, caraway oil, and Janesville were tested against T. confusum and T. castaneum in the laboratory and stored conditions. Encapsulation method by the technology of polymerization was followed. The nano-oils were tested at the concentrations of $0.5 \%$ against the 3rd larval instars. Cumulative percentages of mortality was determined after 7 days of the first applications. The effect of nano-oils on oviposition was carried out by spraying $2 \mathrm{~g}$ of foams of the tested oils and their nanoformulations mixed with $100 \mathrm{~g}$ of wheat.

Results: The results obtained showed that the percentage of larval mortality of T. confusum and T. castaneum increased with an increase in the treatment concentrations. Larvae of T. confusum were more susceptible to the treatments than T. castaneum larvae. Nano Janesville oil was more effective than that of coriander or black seed oil. Fecundity and adult emergence percentage are highly suppressed by nano-formulations of coriander, black seed, or Janesville oils under storage conditions, compared to those of the controls or non-nano-oils.

The results suggested that nano Janesville can be used as a valuable tool in pest management programs of T. confusum and T. castaneum

(Continued on next page)
\end{abstract}

Correspondence: sabbourm@yahoo.com

Department of Pests and Plant Protection, Agriculture Division, National

Research Center, 33rd El Bohouth St., Dokki, Giza, Egypt

(c) The Author(s). 2020 Open Access This article is licensed under a Creative Commons Attribution 4.0 International License, which permits use, sharing, adaptation, distribution and reproduction in any medium or format, as long as you give appropriate credit to the original author(s) and the source, provide a link to the Creative Commons licence, and indicate if changes were made. The images or other third party material in this article are included in the article's Creative Commons licence, unless indicated otherwise in a credit line to the material. If material is not included in the article's Creative Commons licence and your intended use is not permitted by statutory regulation or exceeds the permitted use, you will need to obtain permission directly from the copyright holder. To view a copy of this licence, visit http://creativecommons.org/licenses/by/4.0/. 


\begin{abstract}
(Continued from previous page)
Conclusion: The results of this work indicate that some essential oils might be helpful management of pests in the stores because of their fumigant and odor action. Essential oils of plant origin contain active ingredients that are effective against many insects. Nano-formulations of essential oils, through controlled release, prevent rapid vaporization and degradation and increase the stability of the oils. Treated foam, using coriander, Janesville, caraway, and black seed (habat al Baraka) oils, gave protection against the red flour beetles Tribolium castaneum and confused flour beetle Tribolium confusum.
\end{abstract}

Keywords: Nanotechnology, Essential oils, Tribolium castaneum, Tribolium confusum

\section{Background}

The flour beetles Tribolium confusum Jacquelin du Val, and the red flour beetle Tribolium castaneum (Herbst), are widespread insects that attack stored grains and foods in several commodities. In stores, the adults and larvae feed on broken and fine-ground grains resulting in serious damage to seeds. These pests may give rise to considerable economic losses if not adequately controlled because they have a very high rate of population increase (Abdel Rahman et al. 2014). Natural insecticides of low mammalian toxicity, e.g., diatomaceous earth (DEs), are used against a wide range of insect species. So, it can be inserted into Integrated Stored Grain Insect Management Programs (Subramanyam and Roesli 2000). DEs adhere directly to the insect body to the insect body resulting in absorbing the oily or waxy outer cuticle layer leading to the loss of water and eventually death of insect loses water and dies (Ebeling 1971). Various DE formulations have been estimated against different stored product pests. They are not toxic, easy to be removed from the grains, and possibly recycled in storage bins.

Nanotechnology is a new promising field of research. It shows a wide range in various fields like insecticides, agriculture, pharmaceuticals, and electronics. The possible uses of nanotechnology are massive. The physical, biological, and chemical properties of nanoparticles are associated with their atomic strength (Athanassiou, et al., 2008 $\&$ 2005). Silica nanoparticles do not affect the looseness and bulk density of grain mass-like DE even with the highest dose used (Korunic, 1997). Under laboratory and storage conditions, the nanoparticles of aluminum oxide and titanium oxide highly reduce the infestations of Sitophilus oryzae (Sabbour, 2012). Nanoparticles of Cab-O-Sil-750 and Cab-O-Sil-500 were highly effective in controlling Sitophilus oryzae (Sabbour (2013a and 2013b)

\section{Material and methods}

\section{Tested insects}

Larvae and adults of $T$. castaneum and $T$. confusum reared under laboratory conditions $\left(26 \pm 2{ }^{\circ} \mathrm{C}\right.$ and 70 $80 \%$ R.H. with 16-h light and 8-h dark) on semi-artificial diet consisting of fine wheat with some adherent endosperm with $20 \%$ glycine and $5 \%$ yeast powder.

\section{Essential oils}

Four essential oils were used in the bioassay tests: coriander, oil, Janesville, caraway, and black seed (habat al Baraka). They were obtained by steam distillation of dried plants (Guenther 1961).

Oil emulsions were prepared as follows: 5 drops of Triton X-100 as emulsifier were mixed thoroughly with $5 \mathrm{ml}$ of each tested oil, and then water was added to obtain the desired concentrations (2\%) in percent of $\mathrm{v} / \mathrm{v}$. The emulsifier was mixed at the corresponding concentrations and used as a check. To evaluate the insecticidal activity of tested oils during sequential times $(24,48,96$, and $168 \mathrm{~h}$ ), foam granules $(1 \mathrm{~cm}$ in diameter) were treated at zero time with $2 \%$ of the tested oils dried and provided with heat sterilized rice $100 \mathrm{~g}$ seeds each) fastened each with a string. Then all treatments were used immediately as nonchoice test. The foam particles were treated with the natural oils, which were mixed with stored seeds (2g foam/ 100g seeds) according to (Abd El-Aziz, 2001). Oil emulsions were prepared as follows: 5 drops of Triton X-100 as emulsifier were mixed thoroughly with $5 \mathrm{ml}$ of each tested oil, and then water was added to obtain the desired concentrations $(2 \%)$ in percent of $(\mathrm{v} / \mathrm{v})$. The emulsifier was mixed at the corresponding concentrations and used as a check. To evaluate the insecticidal activity of tested oils during sequential times $(24,48,96$, and $168 \mathrm{~h})$, foam granules $(1 \mathrm{~cm}$ in diameter) were treated at zero time with $2 \%$ of the tested oils dried and provided with heat-sterilized rice $100 \mathrm{~g}$ seeds each, fastened each with a string. Then all treatments were used immediately as non-choice test. The foam particles were treated with the natural oils, which were mixed with stored seeds $(2 \mathrm{~g}$ foam $/ 100 \mathrm{~g}$ seeds) according to Sabbour and Abd El-Aziz (2016).

A pair of newly emerged weevils were placed with treated or untreated rice seeds in glass jars $(250 \mathrm{ml}$ capacity) covered with muslin. The number of dead weevils in each jar was counted every day and percentages of mortality were corrected using Abbott's formula (Abbott 1925). The LC50 was calculated through the probit analysis (Finney 1971). The experiments were conducted under the National Research Centre laboratories conditions of $27 \pm 2{ }^{\circ} \mathrm{C}$ and $60-65 \% \mathrm{R}$. H. The experiment was replicated four times. 


\section{Nanoencapsulation}

It is a process through which a chemical is slowly but efficiently released to the particular host for insect pests control. "Release mechanisms include dissolution, biodegradation, diffusion, and osmotic pressure with specific ( $\mathrm{pH}, 4.4)$ ". The nanoencapsulation process was carried out by polymerization technology. The tested oils were used as a core material and urea (U) and formaldehyde (F) as shell materials. Sulfuric acid solution $(10 \% \mathrm{w} / \mathrm{w})$ was prepared in our laboratory to control the $\mathrm{pH}$ (4.4) of emulsion, and tween 80 (polysorbate 80) was used as an emulsifier (Merck, Germany). The suspension obtained of nanocapsules was cooled down to ambient temperature, rinsed with deionized water, filtered, and finally dehydrated by freeze-drying using a LIO-5P, which is a Freeze Dryers for Laboratory Use. (Apparatus CinquePascal, Trezzano SN, Milan, Italy). Nano-emulsion is prepared by high-pressure homogenization of $2.5 \%$ surfactant and $100 \%$ glycerol, to create stable droplets which that increase the retention of the oil and cause as low release of the nanomaterials. The release rate depends upon the protection time; consequently, a decrease in release rate can prolong insect pests protection time (Quintela and McCoy 1998). For each tested bulk essential oils, four concentrations were prepared

Table 1 The accumulative mortality of T. castaneum and T. confusum during the first week of treated foam with different tested oils

\begin{tabular}{|c|c|c|c|}
\hline Tested oil & Time (days) & T. castaneum & T. confusum \\
\hline \multirow[t]{4}{*}{ Coriander } & 0 & 33.1 & 35.6 \\
\hline & 2 & 46.9 & 47.8 \\
\hline & 4 & 65.2 & 69.5 \\
\hline & 7 & 80.3 & 85.4 \\
\hline \multirow[t]{4}{*}{ Black seed } & 0 & 11.6 & 12.8 \\
\hline & 2 & 20.3 & 22.0 \\
\hline & 4 & 26.1 & 27.7 \\
\hline & 7 & 41.8 & 40.9 \\
\hline \multirow[t]{4}{*}{ Janesville } & 0 & 30.9 & 34.5 \\
\hline & 2 & 44.9 & 47.7 \\
\hline & 4 & 67.1 & 68.8 \\
\hline & 7 & 84.8 & 87.9 \\
\hline \multirow[t]{4}{*}{ Caraway } & 0 & 29.8 & 29.7 \\
\hline & 2 & 34.3 & 35.1 \\
\hline & 4 & 55.8 & 55.8 \\
\hline & 7 & 68.9 & 69.1 \\
\hline \multirow[t]{4}{*}{ Untreated } & 0 & 0.0 & 0.0 \\
\hline & 2 & 0.0 & 0.0 \\
\hline & 4 & 0.0 & 0.0 \\
\hline & 7 & 0.0 & 0.0 \\
\hline$F$ test & & 25.8 & 16.5 \\
\hline Lsd5\% & & 11.2 & 10.4 \\
\hline
\end{tabular}

$(3,1.5,0.5$, and $0.2 \%)$. While in the case of nano-essential oils, the tested concentrations were $0.1,0.5,0.05$, and $0.005 \%$. Three drops of emulsifier (Triton X-100) were mixed with water and used as a check. The tested oils (Bulk \& Nano) were experimented at concentrations tested for their insecticidal activities against the 3rd instar larvae of target pests. According to Abd El-Aziz (2001), the foam granules were sprayed with the tested oils (Bulk \&Nano) and were mixed with wheat ( $2 \mathrm{~g}$ foam $/ 100 \mathrm{~g}$ wheat). For each tested concentration, four glass jars as replicates were used. Thereafter, ten third instar larvae were introduced into each glass jar and covered with muslin for suitable ventilation. In the case of untreated control, twelve replicates were kept under the same conditions without any treatments. After 7 days of exposure, mortality percentages were calculated in the treated and untreated control experiments. All tests were carried at $27 \pm 2^{\circ} \mathrm{C}$ and $65 \pm 5 \%$ relative humidity $(\mathrm{RH})$. The dead larvae numbers were estimated in each jar was used and the mortality percentage was determined. Each experiment was replicated four times. The tested oils (Bulk \&Nano) were sprayed to the foam granules and were mixed with wheat (2 $\mathrm{g}$ foam $/ 100 \mathrm{~g}$ wheat) for testing the oviposition inhibitory effects of tested oils (Abd El-Aziz 2001). In no-choice test, two

Table 2 The accumulative mortality of T. castaneum and $T$. confusum during the first week of treated foam with different tested nano oils

\begin{tabular}{|c|c|c|c|}
\hline Tested oil & Time (days) & T. castaneum & T. confusum \\
\hline \multirow[t]{4}{*}{ Nano Coriander } & 0 & 55.9 & 56.6 \\
\hline & 2 & 66.9 & 68.3 \\
\hline & 4 & 79.3 & 79.6 \\
\hline & 7 & 89.3 & 89.7 \\
\hline \multirow[t]{4}{*}{ Nano black seed } & 0 & 20.5 & 20.2 \\
\hline & 2 & 29.1 & 29.9 \\
\hline & 4 & 38.5 & 39.1 \\
\hline & 7 & 40.8 & 40.9 \\
\hline \multirow[t]{4}{*}{ Nano Janesville } & 0 & 45.8 & 46.2 \\
\hline & 2 & 65.9 & 66.9 \\
\hline & 4 & 77.2 & 79.3 \\
\hline & 7 & 84.3 & 85.7 \\
\hline \multirow[t]{4}{*}{ Nano Caraway } & 0 & 28.2 & 30.2 \\
\hline & 2 & 34.3 & 35.7 \\
\hline & 4 & 59.1 & 59.8 \\
\hline & 7 & 74.7 & 77.9 \\
\hline \multirow[t]{4}{*}{ Untreated } & 0 & 0.0 & 0.0 \\
\hline & 2 & 0.0 & 0.0 \\
\hline & 4 & 0.0 & 0.0 \\
\hline & 7 & 0.1 & 0.1 \\
\hline F test & & 18.9 & 16.4 \\
\hline Lsd5\% & & 10.1 & 10.4 \\
\hline
\end{tabular}


Table 3 Effect of the tested essential oils and nano-oils on eggs number laid per female and \% of adult emergence (F1) of T. castaneum during storage periods

\begin{tabular}{llll}
\hline Tested materials & Means no. of eggs / + \pm S.E. & \% adult emergence (F1) & \%. of emerged adult malformation. \\
\hline Nano , Coriander & $7.4 \pm 3.89$ & 1 & 100 \\
Nano black seed oil & $61.4 \pm 7.81$ & 21 & 40 \\
Nano Janesville & $29.4 \pm 1.87$ & 12 & 89 \\
Nano caraway & $10.9 \pm 8.21$ & 4 & 99 \\
Control & $299.4 \pm 1.88$ & 100 & 0 \\
F test & 37.7 & & \\
Lsd5\% & 18.9 & & \\
\hline
\end{tabular}

pairs of mixed-sex of target moth adults (2-3 days old) were placed with treated or untreated wheat grains with foam particles in glass jars (250 cc capacity) covered with muslin. Adults female moths were left to lay their eggs, then the deposited egg numbers treated or untreated the grains/female were estimated in each of the tested jars. Four glass jars as replicates for each tested concentration were used and the test was repeated three times. The persistence effect of tested oils (Bulk and Nano) on foam as surface protectant was evaluated after storage interval 120 days (4 months) against target pests moths' emergence. Hundred grams of heat sterilized wheat grains were introduced to gunny sacks $(10 \times 10 \mathrm{~cm}$ each) closed each with a string. The foam granules (about 1 $\mathrm{cm}$ in diameter) were sprayed with treatments, dried, and provided as a layer between sacks. Then, two pairs of newly emerged moths were placed in a jar (21 capacity with two gunny sacks) and then removed the moths which died after lying egg. The count of the newly emerged adult moths after 120 days is about 4 months.

\section{Statistical analysis}

Data were statistically analyzed by $F$ test; LSD value was estimated, using SPSS statistical program software.

\section{Results}

Table 1 shows coriander oil followed by Janesville oil which gave the highest mortality percentage after 7 days 80.3 and $85.4 \%$, respectively, for T. castaneum and 84.8 and $87.9 \%$ for
T. confusum as compared to control. The percentages of the accumulation mortality of both the target pests showed that the Janesville was the highest oil affected on mortality, which reached to 30.2 and 32.7 for T. castaneum and T. confusum after 0 days as compared to $0 \%$ in the control. After 7 days, the percentages of mortality reached 64.3 and $67.9 \%$ for the corresponding insects as compared to 0.2 and $0.1 \%$ in the control (Table 1)

Table 2 shows that the most effective nano-oils tested significantly decreased after 7 days of the first applications. When the nano-coriander was applied after 7 days, the percentage reached 89.3 and $98.7 \%$, for T. castaneum and T. confusum, respectively (Table 2 ). Data in Table 2 show the effect of the nano-oils tested against the two pests which gave 85.3 and $89.9 \%$ mortality of T. castaneum and T. confusum when treated with nano-Janesville after 7 days compared to 0.1 and $0.1 \%$ in the control.

Table 3 shows that the nano-oils affected the female fecundity of $T$. castaneum; the number of eggs laid/female was significantly decreased by 40.45 fold after nano coriander treatments. The percentages of malformations reached to $100 \%$. When $T$. castaneum was treated with nano Janesville, the percentages of $T$. castaneum significantly decreased by 27.46 -fold and the malformed percentages of adults reached to $99 \%$ (Table 3). The effect of the tested nano-oils on the eggs laid/female found in Table 3 revealed that the mean number of eggs laid per female was significantly decreased to $10.4 \pm 9.89,21.4 \pm$

Table 4 Effect of the tested essential oils and nano-oils on eggs number laid per female and \% of adult emergence (F1) of T. confusum during storage periods

\begin{tabular}{llll}
\hline Tested materials & no. of eggs $/$ + S.E. & \% adult emergence (F1) & \%. of emerged adult malformation. \\
\hline Nano Coriander & $5.3 \pm 1.0$ & 0.1 & 99 \\
Nano black seed oil & $60.4 \pm 1.21$ & 19 & 52 \\
Nano Janesville & $30.4 \pm 6.28$ & 11 & 88 \\
Nano Caraway & $16.4 \pm 1.28$ & 5.7 & 09 \\
Control & $297.9 \pm 7.89$ & 100 & 0 \\
F test & 33.1 & & \\
Lsd5\% & 18.1 & & \\
\hline
\end{tabular}




\section{Replancy test of nano essential oils on Tribolium \\ castaneum}

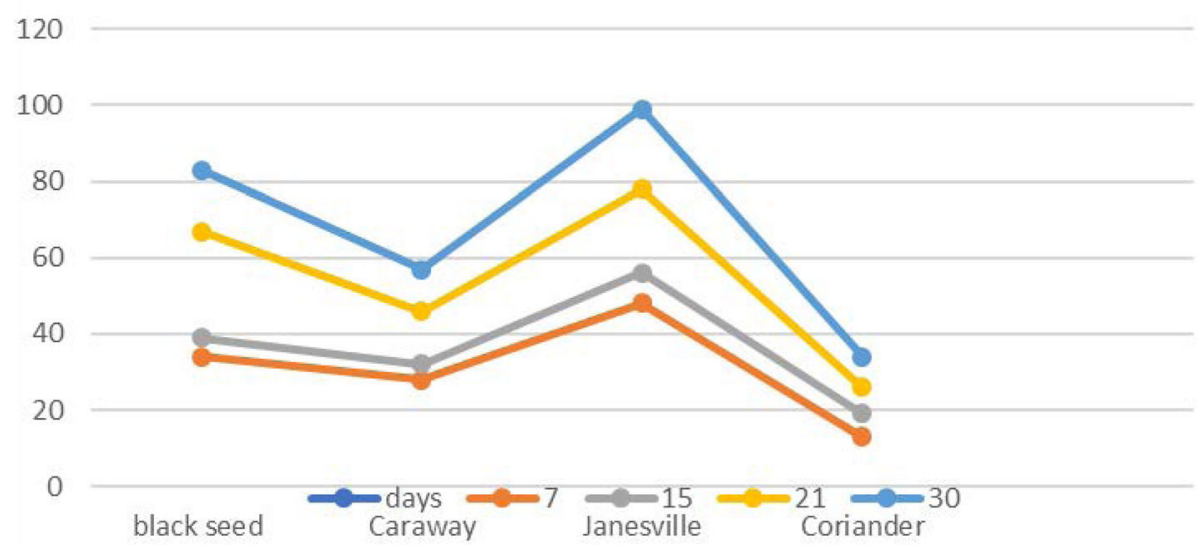

Fig. 1 The repellent activity of the tested essential nano-oils on T. castaneum

7.81, and $9.4 \pm 1.87$ eggs/female after treatment with nano coriander, nano black seed, and nano Janesville, respectively, as compared to $299.4 \pm 1.88 \mathrm{eggs} / \mathrm{female}$ in the control (Table 4). Table 4 shows that the number of eggs laid/female due to treatments of $T$. castaneum with nano coriander, nano black seed oil, and nano Janesville reached $10.3 \pm 0.0,20.4 \pm 1.21$, and $10.4 \pm$ 5.38 eggs/female, respectively, as compared to $297.9 \pm$ 7.89 eggs/female in the control, respectively. Figures 1 and 2 show that the nano-oils tested were repellant to $T$. castaneum and T. confusum especially, in the case of treatment with coriander.

\section{Discussions}

The nano-oils decreased the infestations number of the target insect pests $T$. confusum and $T$. castaneum, under laboratory and field conditions. In this respect, Sabbour (2019) found that the nano-oils reduce the infestation number of $C$. maculatus and C. chinensis. These results are consistent with those obtained by Sabbour and Abd El-Aziz (2019), who reported that the incorporation of essential oils into a controlled release nano-formulations prevented rapid vaporization and degradation, increased constancy, and preserved the lower effective dosage/application. Also, the treated foam

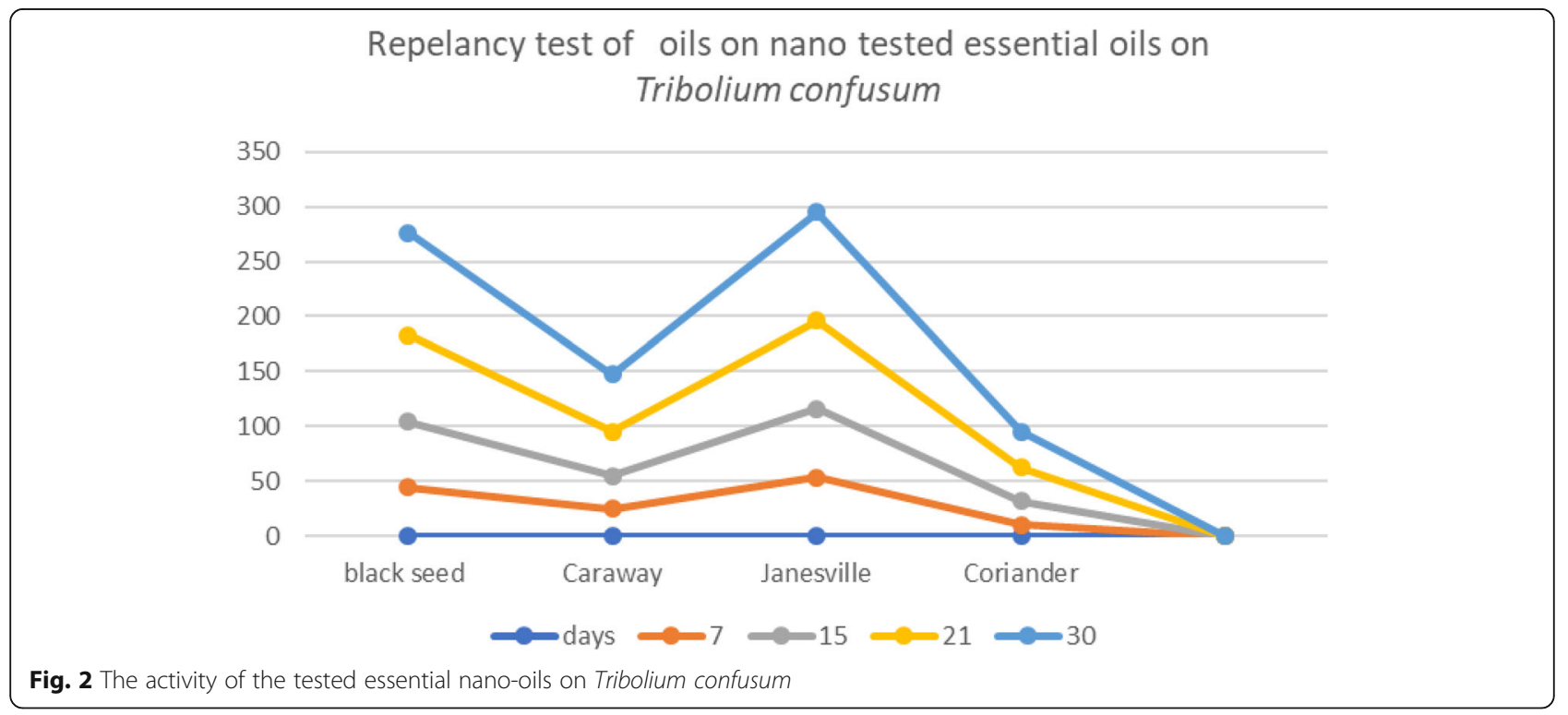


with nano rosemary and nano eucalyptus oil and covering gunny bags provided many efficient effects against Ephestia kuehniella and E. cautella (Sabbour and Shadia Abd El-Aziz 2019).

Padina et al. (2002) found that the Tribolium castaneum, causing seeds loss, may be controlled by the entomopathogenic fungi. Results are with Kim et al. (2010).

The action of essential oils against stored- product insects has been extensively studied and proved a repellancy of the insect larvae of T. castaneum. Sabbour and Abd El-Aziz, 2010; Sabbour and Abd El-Aziz, 2017; Sabbour and Abd El-Aziz, 2018) stated that the essential oils andnano essential oils have agreat replencey effect on stord produt insects during the storage preiod. they also, confirmed that the incorporation of tested nano -essential oils into a controlled release prevent with rapid vaporization, increases the constancy, causing a degradation and preserves the lower effective application dose.

Similar results were obtained by Sabbour and Abd El-Aziz (2018 and 2019), who found that the larvae of $T$. confusum were more susceptible to the nanotreatments than $T$. castaneum larvae and the Nano-DE was more effective than natural DE. The larval mortality percentage of $T$. confusum recorded 45,39 , and $29 \%$ and 70,65 , and $49 \%$ in the case of DE and nano-DE at 1.0, 0.5, and $0.25 \%$ concentrations, respectively, in comparison to $2 \%$ mortality in the untreated control. Similar results obtained by Shahmirzaei et al. (2016) mentioned that the fumigant toxicity of $M$. longifolia oil is more powerful than its contact toxicity. Using the technique of nanoemulsion can increase the contact activity of essential oil and its strength, out of the slow-release of active ingredients over time.

Sabbour (2013a, 2013b) found that M. anisopliae and Beauveria bassiana when combined with some extract oils could decrease the infestations of wheat and flour pests under laboratory and store conditions. Also, our results agree with Yang et al. (2009) who found that the activity of nanoparticles and essential oil is free garlic against red flour beetle. They cleared that the control effectiveness of the nanoparticles of garlic oil gave about $80 \%$ which followed by the garlic oil at concentrations of $11 \%$. The combinations of biopesticided are recoded by Sabbour et al., 2014 who mentioned that the B.t suppress the infections of $T$. confusum and T. castneum under store conditions. The same obtains recoded by Sabbour $(2014,2015)$ found that the combinations of inorganic material and fungi reduce the number of stored pests $T$. confusum and T. castneum under store conditions. The same results obtained by Sabbour and Abd El Raheem (2015a \& 2015b, 2016)

Similar results were obtained by Sabbour and Abd El Raheem (2016); three oils tested with the combinations with the fungus $B$. bassiana decreased the infestations of flour pests. The same obtained by Sabbour and Shadia Abd El Aziz (2010, 2015, 2016, 2017, 2018). Sabbour and Abd-El-Aziz (2017) registered that the tested essential oils have a repellent action whereby the insect cannot come in contact with the grain.

\section{Conclusion}

The present study showed that the nano-oils of coriander, Janesville, and caraway were the most effective oils against $T$. castaneum and $T$. confusum. These results will be important and beneficial for controlling many these pests. Our results encourage the extension in the use of nanotechnology for pest control. Furthermore, essential oils are highly selective to insects. Incorporation of essential oils into a controlled release nano-formulation prevents rapid vaporization and degradation, increases constancy, and preserves the lower effective dosage/application.

These results established the criteria on which to base future experiments under simulated farmer storage practice.

\section{Abbreviations \\ DE: Natural diatomaceous earth; E. cautella: Ephestia cutella; E. kuehniella: Ephestia kuehniella; S. oryzae: Sitophilus oryzae; T. \\ castaneum: Tribolium castaneum; T. confusum: Tribolium confusum}

\section{Acknowledgements}

The author Magda Mahmoud Amin Sabbour is very thankful to Pests and Plant Protection Department and Agriculture and Biological Division, National Research Centre, for all the facilities during this work.

\section{Author's contributions}

The author Magda Mahmoud Amin Sabbour equally contributed in all the article parts. Dr Sabbour contributed to putting the idea, designed the experiments, make the laboratory and store experiments, made the statistical analysis and writing the research, and finally, reviewed, read, and approved the final version of the manuscript. The author read and approved the final manuscript.

\section{Authors' information}

Prof. Dr. Magda Sabbour prof. at National Research Centre, Dokki, Giza, Pests and Plant Protection Department; Agricultural and Biological Division.

\section{Funding}

This work was supported and funded by National Research Centre through the project titled (Some strategies for improving weed control efficacy in some export crops). Project No. (11030139), during in-house projects strategy 2016-2019.

Availability of data and materials

Not applicable for this section.

Ethics approval and consent to participate

Not applicable for this section.

Consent for publication

Not applicable for this section.

Competing interests

The authors declare that they have no competing interests. 
Received: 7 February 2020 Accepted: 12 May 2020

Published online: 02 July 2020

\section{References}

Abbott WW (1925) A method of computing the effectiveness of an insecticide. J. Econ. Entomology 18:265-267

Abd El-Aziz SE (2001) Persistence of some plant oils against the Bruchid beetle, Callosobruchus maculates (F.) (Coleoptera: Bruchidae) during storage. Arab Univ J Agric Sci,.9 (1): 423-432. https://www.researchgate.net/publication/2 99337223_Persistence_of_some_plant_oil

Abdel Rahman H, Abd-El-Aziz SE, Omar EA, Abdel-Hakim EA, Fahim SF (2014) Olfaction cues of food odours influencing behavior response of the red flour beetle, Tribolium castanium (Herbst) ( Coleoptera: Tenebrionidae). Bull. NRC 39(1):1-11 https://www.ncbi.nlm.nih.gov/pubmed/30010815

Athanassiou CG, Kavallieratos NG, Vayias BJ, Panoussakis EC (2008) Influence of grain type on the susceptibility of different Sitophilus oryzae (L.) populations, obtained from different rearing media, to three diatomaceous earth formulations. J. Stored Prod. Res 44:279-284 https://www.sciencedirect.com/ science/article/pii/S0022474X08000234

Athanassiou CG, Vayias BJ, Dimizas CB, Kavallieratos NG, Papagregoriou AS, Buchelos CT (2005) Insecticidal efficacy of diatomaceous earth against Sitophilus oryzae (L.) (Coleoptera: Curculionidae) and Tribolium confusum Jacquelin du Val (Coleoptera: Tenebrionidae) on stored wheat: influence of dose rate, temperature and exposure interval. J. Stored Prod. Res. 41:47-55 https://scialert.net/abstract/?doi=pjbs.2005.3841.3846

Ebeling W (1971) Sorptive dust for pest control. Ann. Rev. Entomol. 16(1):123-158

Finney DJ (1971) Probit Analysis. Cambridge University Press

Guenther G (1961) The Essential Oils VIII. Robert E.D. Nastrand Company Inc., Toronto Hassan, A.E.M. and Charnley, K.A. 1989: Ultrastructural study of penetration by Manduca sexta. J. Inv. Path., 54: 117-124.

Kim S, Yoon JS, Jung JW, Hong KB, Ahn YJ, Kwon HW (2010) Toxicity and repellency of Origanum essential oil and its components against Tribolium castaneum (Coleoptera: Tenebrionidae) adults. J Asia Pac Entomol 13:369-373. https://doi.org/10.1016/j.aspen.2010.06.011

Korunic Z (1997) Diatomaceous earths, a group of natural insecticides. J.Stored Prod. Res., 34:87-97, Against Sitophilus oryzae Under Laboratory and Store Conditions in Egypt. J Sci. Res. Reports, 1 (2): 67-74. https://www. researchgate.net/publication/280287250

Padina S, Dal Belloa G, Fabriziob M (2002) Grain loss caused by Tribolium castaneum, Sitophilus oryzae and Acanthoscelides obtectus in stored durum wheat and bean treated with Beauveria bassiana. J Stored Prod Res 38(1): 69-74. https://doi.org/10.1016/50022-474X(00)00046-1

Quintela ED, McCoy CW (1998) Synergistic effect of imidacloprid and two entomopathogenic fungi on the behavior and survival of larvae of Diaprepes abbreviates (Coleoptera: Curculionidae) in soil. J Econ Entomolol 91: 110-122. Available on: http://www.crec.ffas.ufl.edu/extension/diaprepes/bibliography/ PDF/JouEcoEnt991.pdf

Sabbour MM (2012) Entomotoxicity assay of two nanoparticle materials 1-(Al2O3and TiO2) against Sitophilus oryzae under laboratory and store conditions in Egypt. J Novel Appl Sci. 1-4:103-108 https://www. semanticscholar.org/paper/Entomotoxicity-assay-of-two-Nanoparticle-Mat

Sabbour MM (2013a) Entomotoxicity assay of nanoparticle 4-(silica gel Cab-O-Sil750, silica gel Cab-O-Sil-500). Specialty Journal Of Biological Sciences. Volume 1, 2015,2. https://sciarena.com/en/article/entomotoxicity-assay-ofnanoparticle-4-silica-gel-cab-o-s

Sabbour MM (2013b) Entomotoxicity assay of nano-particle 3-(Zinc oxide ZnO) against Sitophilus oryzae under laboratory and store conditions in Egypt. J Sci Res Rep, 1 (2): 50-57. https://pdfs.semanticscholar.org/1 fc9/4c327640774 of1e9eba5fc42ce4694bbdacf.pdf

Sabbour MM (2014) Efficacy of some microbial control agents and inorganic insecticides against red flour beetle Tribolium castaneum and confused flour beetle, Tribolium confusum (Coleoptera: Tenebrionidae) Integrated Protection of Stored Products. IOBC-WPRS Bulletin Vol. 98, 2014.pp. 193-201. https://www.academia.edu/8191457/Efficacy_of_some_microbial_control_ agents_and_inorganic

Sabbour MM (2015) Efficacy of some nano-Imidacloprid against red flour beetle Tribolium castaneum and confused flour beetle, Tribolium confusum (Coleoptera: Tenebrionidae) under laboratory and store conditions. Advances in Biochemistry \& Biotechnology. 1-13.

Sabbour MM (2019) Efficacy of natural oils against the biological activity on Callosobruchus maculatus and Callosobruchus chinensis (Coleoptera:
Tenebrionidae). Bulletin of the National Research Centre 43:206. https://doi.org/10.1186/s42269-019-0252-1.

Sabbour MM, Shadia El-Sayed, Abd-El-Aziz (2015) Efficacy of some nanodiatomaceous earths against red flour beetle Tribolium castaneum and confused flour beetle, Tribolium confusum (Coleoptera: Tenebrionidae) under laboratory and store conditions. Bull. Env.Pharmacol. Life Sci., Vol 4 [7] 2015: 54-59. https://pdfs.semanticscholar.org/1fc9/4c3276407740f1 e9eba5fc42ce46 94bbdacf.pdf

Sabbour MM, Shadia El-Sayed Abd El-Aziz (2018) The combined effect of Metarhizium anisopliae and some natural oils against Ephestia kuehniella and Ephestia cutella (Lepidoptera: Pyralidae) under laboratory and store conditions. Bioscience Research 15(4): 3480-3489. https://doi.org/10.1186/ s42269-019-0129-3

Sabbour MM, Shadia El-Sayed Abd El-Aziz* (2019) Impact of certain nano oils against Ephestia kuehniella and Ephestia cutella (Lepidoptera-Pyralidae) under laboratory and store conditions. Bulletin of the National Research Centre (2019) 43:80. https://doi.org/10.1186/s42269-019-0129-3.

Sabbour MM, Abd-El-Aziz SE (2010) Efficacy of some bioinsecticides against Bruchidius incarnatus (Boh.) (Coleoptera: Bruchidae) infestation during storage. J Plant Prot Res 50(1):25-31. https://doi.org/10.2478/v10045-010-0005-5

Sabbour MM, Abd-El-Aziz SE (2016) Efficacy of three essential oils and their nanoparticles against Sitophilus granarius under laboratory and store conditions. J Entomol Res 40(3):229-234. https://doi.org/10.5958/0974-4576.2016.00042.6

Sabbour MM, Abd-El-Aziz SE (2017) Screening effects of three natural oils and their nano against Ephestia kuehniella (Lepidoptera-Pyralidae) in laboratory and store. Biosci Res 14(2):408-416. https://doi.org/10.1186/s42269-019-0129-3

Sabbour MM, Abd-El-Aziz SE (2018) The combined effect of Metarhizium anisopliae and some natural oils against Ephestia kuehniella and Ephestia cutella (Lepidoptera- Pyralidae) under laboratory and store conditions. Biosci Res 15(4):3480-3489. https://doi.org/10.1186/s42269-019-0129-3

Sabbour MM, Foda MS, Maysa E Moharam (2014) Evaluations of Bacillus species against red flour beetle Tribolium castaneum and confused flour beetle, Tribolium confusum (Coleoptera: Tenebrionidae) under laboratory and store conditions. European Journal of Academic Essays 2(1): 36-41, 2014. https:/pdfs.semanticscholar.org/6339/d63e4f7169df8cc75522c0ce6ebd0f6 07d3c.pdf

Sabbour M, Abdel-Raheem MA (2015a) Determinations the efficacy of Beauveria brongniartii and Nomuraea rileyi against the potato tuber moth Phthorimaea operculella (Zeller). Am J Innov Res Appl Sci. 1202-197. https://www.scribd. com/document/274853781/EFFICACY-OF-BEAUVERIA-BRONGN

Sabbour M, Abdel-Raheem MA (2015b) Toxcicty of the fungus Beauveria bassiana and three oils extracted against Sitophilus granries under laboratory and store conditions. Am J Innov Res Appl Sci. 251-256. https://www.researchgate.net/ publication/249887008_Efficacy_of_Beauveria_bassia.

Sabbour M, Abdel-Raheem MA (2016) Nano Imidacloprid efficacy against the desert locust, Schistocerca gregaria under laboratory and semi field conditions Der Pharma Chemica, 2016, 8(4):133-136. https://www. derpharmachemica.com/pharma-chemica/nano-imidacloprid-efficacyagainst-

Shahmirzaei Z, Izadi H, Imani S (2016) Study on the contact and fumigant toxicity of Mentha longifolia $\mathrm{L}$. against the confused flour beetle (Tribolium castaneum). Iran J Med Arom Plants 32:556-559 https:/www.researchgate.net/publication/2356 46208_Insecticide_Activity_of_Essential_

Subramanyam Bh, Roesli R. (2000). Inert dusts. In: Alternatives to pesticides in stored-product IPM (eds. https://www.springer.com/gp/book/9780792379768

Yang FL, Li XG, Zhu F, Lei CL (2009) Structural characterization of nanoparticles loaded with garlic essential oil and their insecticidal activity against Tribolium castaneum (Herbst) (Coleoptera: Tenebrionidae). J Agric Food Chem 57: 10156 -10162. https://doi.org/10.1021/ff9023118.

\section{Publisher's Note}

Springer Nature remains neutral with regard to jurisdictional claims in published maps and institutional affiliations. 